\title{
The Dark Side of Self- and Social Perception: Black Uniforms and Aggression in Professional Sports
}

\author{
Mark G. Frank and Thomas Gilovich \\ Cornell University
}

\begin{abstract}
Black is viewed as the color of evil and death in virtually all cultures. With this association in mind, we were interested in whether a cue as subtle as the color of a person's clothing might have a significant impact on his or her behavior. To test this possibility, we examined whether professional football and ice hockey teams that wear black uniforms are more aggressive than those that wear nonblack uniforms. An analysis of the penalty records of the National Football League and the National Hockey League indicate that teams with black uniforms in both sports ranked near the top of their leagues in penaities throughout the period of study. On those occasions when a team switched from nonblack to black uniforms, the switch was accompanied by an immediate increase in penalties. The results of two laboratory experiments indicate that this finding can be attributed to both social perception and self-perception processes--that is, to the biased judgments of referees and to the increased aggressiveness of the players themselves. Our discussion focuses on the theoretical implications of these data for an understanding of the variable, or "situated," nature of the self.
\end{abstract}

A convenient feature of the traditional American Western film was the ease with which the viewer could distinguish the good guys from the bad guys: The bad guys wore the black hats. Of course, film directors did not invent this connection between black and evil, but built upon an existing association that extends deep into our culture and language. When a terrible thing happens on a given day, we refer to it as a "black day," as when the Depression was ushered in by the infamous "Black Thursday." We can hurt ourselves by "blackening". our reputation or be hurt by others by being "blacklisted," "blackballed," or "blackmailed" (Williams, 1964). When the Chicago White Sox deliberately lost the 1919 World Series as part of a betting scheme, they became known as the Chicago Black Sox, and to this day this "dark" chapter in American sports history is known as the Black Sox Scandal. In a similar vein, Muhammed Ali has observed that we refer to white cake as "angel food cake" and dark cake as "devil's food cake."

These anecdotes concerning people's negative associations to the color black are reinforced by the research literature on color meanings. In one representative experiment, groups of college students and seventh graders who were asked to make semantic differential ratings of colors were found to associate black with evil, death, and badness (Williams \& McMurty, 1970). More-

This research was supported, in part, by National Institute of Mental Health Grant MH39083 to the second author.

We would like to thank Mike Herb, Greg Jok, Kevin O'Shaughnessy, Bob Seyfried, Chuck Suhay, Mike Tato, and Will Zickle for risking injury as the football players filmed in Study 3. We are also grateful to Lauren Ostergren and Mark Schmuckler for their assistance in collecting our data and to Daryl Bem for commenting on an earlier version of the manuscript.

Correspondence concerning this article should be addressed to Mark Frank or Thomas Gilovich, Department of Psychology, Uris Hall, Cornell University, Ithaca, New York 14853. over, this association between black and evil is not strictly an American or Western phenomenon, because college students in Germany, Denmark, Hong Kong, and India (Williams, Moreland, \& Underwood, 1970) and Ndembu tribesmen in Central Africa (Turner, 1967) all report that the color black connotes evil and death. Thus, Adams and Osgood (1973) concluded that black is seen, in virtually all cultures, as the color of evil and death.

The intriguing question is whether these associations influence people's behavior in important ways. For example, does wearing black clothing lead both the wearer and others to perceive him or her as more evil and aggressive? More important, does it lead the wearer to actually act more aggressively? ?

This possibility is suggested by studies on anonymity and "deindividuation" which show that a person's clothing can affect the amount of aggression he or she expresses. In one study, female subjects in a "learning" experiment were asked to deliver shocks to another subject whenever she made a mistake. Under the pretense of minimizing individual identities, one half of the subjects wore nurses uniforms (a prosocial cue), and the other half wore outfits resembling $\mathrm{Ku}$ Klux Klan uniforms (an antisocial cue). As predicted, subjects who wore nurses uniforms delivered less shock to the "learner" than did subjects who wore the Ku Klux Klan uniforms, which demonstrates that the cues inherent in certain clothes can influence the wearer's aggressive behavior (Johnson \& Downing, 1979).

Although such studies are suggestive, they involve rather contrived situations that raise troubling questions of ecological validity and experimental demand. Accordingly, we decided to seek parallel evidence for a link between clothing cues and aggressiveness by examining the effect of a much more subtle cue, the color of a person's uniform, in a more ecologically valid context. In particular, we examined the aggressiveness of teams with black uniforms in two professional "contact" sportsfootball and ice hockey. Do teams with black uniforms appear 
to play with greater aggressiveness than those with nonblack uniforms, and if so, what are the processes that produce this effect?

Our investigation of the relationship between uniform color and aggressiveness is divided into four parts. First, we investigated whether different colored uniforms carry the same connotations as the basic colors themselves. Do the uniforms of the black-uniformed teams in the National Football League (NFL) and the National Hockey League (NHL) look more evil, mean, and aggressive than the uniforms of the nonblack-uniformed teams? Next we analyzed the penalty records from these two leagues to test whether the teams with black uniforms are penalized more than their rivals. If the evil connotations of the color black lead those who wear black uniforms to act unusually aggressively, then the teams with black uniforms in the NFL and the NHL should be penalized more than other teams. Finally, we conducted two experiments designed to test whether the results obtained in our analysis of penalty records were due to the uniforms' effect on the referees' judgments (Study 3) or on the players' actual behavior (Study 4). We conclude with a discussion of the theoretical implications of our results, a discussion that focuses on the variable, or "situated," nature of the self.

\section{Study 1: Semantic Differential Ratings of Team Uniforms}

\section{Method}

Because a uniform is a much more complex stimulus than a swatch of color, it was necessary to determine whether people's general associations to certain colors also apply to their perceptions of specific colored uniforms. Thus, 25 subjects were paid $\$ 2$ to make semantic differential ratings of the uniforms of all teams in the NFL and the NHL. The subjects were unfamiliar with either football or ice hockey: They did not know the rules of either game, nor were they able to recognize the uniforms of any of the teams. Only such "naive" subjects were used in this study to ensure that their ratings were determined solely by the characteristics of the uniforms themselves and not by the reputations of the teams that wear them.

The subjects ( 22 females and 3 males) were run in groups, 10 in one group and 15 in another. Subjects were shown color slides depicting the uniforms of all NFL and NHL teams. The slides were taken of the offcial team uniform and color swatches provided by the two leagues. The slides showed the jerseys, pants, socks, and helmets of each team. There were no players modeling the uniforms. Clues to a team's home city were eliminated unless they constituted an integral part of the uniform.

The subjects rated each uniform on five 7-point semantic differential scales: good/bad, timid/aggressive, nice/mean, active/passive, and weak/strong. Each slide was presented for $30 \mathrm{~s}$. The entire experiment took $25 \mathrm{~min}$

\section{Results}

We considered a team to have a black uniform if at least $50 \%$ of its "colored"1 uniform was black. Thus, if a team's base jersey color was black, or if its pants, helmet, and trim were black, then it was categorized as a black-uniformed team. These criteria resulted in five NFL teams with black uniforms-the Pittsburgh Steelers, the New Orleans Saints, the Los Angeles Raiders, the Cincinnati Bengals, and the Chicago Bears. ${ }^{2}$ Likewise, there were five NHL teams with black uniforms-the
Vancouver Canucks, the Pittsburgh Penguins, the Philadelphia Flyers, the Chicago Black Hawks, and the Boston Bruins.

The three scales that directly concern badness and aggressiveness-good/bad, nice/mean, and timid/aggressive-were all positively intercorrelated (median $r=.67$ ). As a result of their statistical and conceptual interconnection, subjects' ratings on these three scales were combined to form one overall "malevolence" index. The mean malevolence ratings of the uniforms in both leagues are presented in Table 1. If we look first at the NFL teams, the black uniforms ( $M d n=4.97$ ) have a decidedly more malevolent appearance than the nonblack uniforms $(M d n=$ 3.85), Mann-Whitney test, $p<.001{ }^{3}$ The results are nearly identical for the NHL teams as well (median malevolence ratings of 5.13 vs. 3.85 ), $p<.003$.

Less consistent results were obtained on the two other semantic differential ratings. The black uniforms in the NFL were also rated as more "strong" ( $M d n=5.60)$ than the nonblack uniforms $(M d n=4.65)$, Mann-Whitney $Z=3.03, p<.005$, and although there was a similar trend in the ratings of the NHL uniforms (black $M d n=5.05$, nonblack $M d n=4.63$ ), the difference in these latter ratings was not significant, $p>.20$. These results are consistent with earlier research in which the color black was shown to connote strength (Adams \& Osgood, 1973). Interestingly, although past research indicates that black is generally seen as a passive color, the black uniforms in both the NFL and the NHL were rated as marginally more active ( $M d n \mathrm{~s}=4.9$ and 5.15 for football and hockey, respectively) than the nonblack uniforms ( $M d n s=4.55$ and 4.65): $Z=1.89, p<$ .10 , for the NFL; $U=21, p<.10$, for the NHL.

We thus have clear evidence that the black uniforms worn by teams in professional football and ice hockey look more malevolent (as well as somewhat more active and strong) than the nonblack uniforms worn by other teams. It remains to be seen whether this difference in people's associations to black and

\footnotetext{
${ }^{1}$ Teams in both sports have two uniforms: a "colored" uniform that is dominated by the team's primary color, and a "noncolored" uniform that is almost always predominately white and utilizes the team's primary color only for the trim and the players' numbers. The dark uniforms are worn by the visiting team without exception in the NHL and by the home team on most occasions in the NFL.

${ }_{2}^{2}$ The Bears actually wear dark blue uniforms, but they are generally perceived to be black. For example, when we asked a random sample of 15 football fans at Cornell to name, from memory, the uniform colors of several NFL teams, 13 of the 15 stated that the Bears' uniforms were black. Even people with close ties to the NFL see them as black, as evidenced by the statement of CBS commentator and former NFL coach John Madden during a 1985 encounter between the Bears and the Dallas Cowboys that "the Bears have got to get those black helmets on the ball carrier." Because it is perceived color that is likely to influence a team's penalty record, we included the Bears as one of the black-uniformed teams. However, it should be pointed out that all significant differences reported in this article between teams with black and nonblack uniforms remain significant if the Bears are treated as one of the teams with nonblack uniforms.

${ }^{3}$ All alpha levels reported in Studies 1 and 2 are based on MannWhitney tests of the relevant data. We report only the alpha levels whenever the raw data are presented in one of the tables, and we report the Mann-Whitney statistics ( $U$ or $Z$, depending on the sample size) when they are not. Mann-Whitney tests were chosen over $t$ tests to protect against the adverse effects of outliers.
} 
Table 1

Malevolence Ratings of the Uniforms of Professional Football and Hockey Teams

\begin{tabular}{|c|c|c|c|}
\hline Football team & Rating & Hockey team & Rating \\
\hline LA RAIDERS & 5.10 & VANCOUVER & 5.33 \\
\hline PITTSBURGH & 5.00 & PHILADELPHIA & 5.17 \\
\hline NEW ORLEANS & 4.83 & New Jersey & 4.45 \\
\hline CHICAGO & 4.68 & PITTSBURGH & 4.27 \\
\hline Kansas City & 4.58 & CHICAGO & 4.18 \\
\hline Washington & 4.40 & Montreal & 4.18 \\
\hline LA Rams & 4.10 & Calgary & 4.13 \\
\hline Cleveland & 4.05 & LA Kings & 4.05 \\
\hline San Diego & 4.05 & Minnesota & 4.00 \\
\hline Green Bay & 4.00 & Buffalo & 4.00 \\
\hline Philadelphia & 3.97 & NY Rangers & 3.90 \\
\hline Minnesota & 3.90 & NY Islanders & 3.80 \\
\hline Tampa Bay & 3.77 & Hartford & 3.32 \\
\hline New England & 3.60 & & \\
\hline Buffalo & 3.53 & & \\
\hline Detroit & 3.38 & & \\
\hline NY Giants & 3.27 & & \\
\hline Dallas & 3.15 & & \\
\hline Houston & 2.88 & & \\
\hline Miami & 2.80 & & \\
\hline
\end{tabular}

Note. Teams in boldface capitals are those with black uniforms. The malevolence ratings represent the average rating of three semantic differential scales: good/bad, timid/aggressive, and nice/mean.

nonblack uniforms is related to how often these teams are penalized.

\section{Study 2: Analyses of NFL and NHL Penalty Records}

Are teams with black uniforms in the NFL and NHL penalized more often than their opponents in nonblack uniforms? To answer this question, we obtained the official penalty records of NFL and NHL teams from 1970 to the most recently completed season in each sport (the 1986 season for the NFL and the $1985 / 1986$ season for the NHL). The records were obtained from the central offices of both leagues. We started our analysis at the 1970 season because that was the year the NFL merged with the now defunct American Football League to form one league with a single set of rules and a common group of referees. We used the same cutoff point for the NHL records simply to get a comparable data set. Furthermore, had we gone back any farther in the NHL record book, we would shortly have been in an era when only six professional hockey teams existed.

\section{The National Football League}

Nearly all penalties in professional football involve moving the football a certain distance (usually 5,10 , or $15 \mathrm{yds}$ ) away from the goal to which the offending team is heading. The league office provided us with complete records of both the number of penalties incurred by each team and the total num- ber of yards penalized. Because penalties for overaggressiveness are generally more severe (e.g., 15 yds for "spearing," "clipping," or a "headslap") than for infractions having little to do with aggressiveness (e.g., 5 yds for "offsides," "illegal motion," or "delay of game"), we selected the number of yards penalized as the better measure of how aggressively a team plays the game.

All teams were ranked in terms of the number of yards penalized for each of the seasons from 1970 to 1986 . The average ranking of the five teams with black uniforms was then calculated and compared to the average to be expected if they were no more likely to be penalized than their opponents (i.e., the average rank of all teams). As predicted, teams with black uniforms in the NFL are uncommonly aggressive: In all but one of the last 17 years these five teams were penalized more yards than one would expect under the appropriate null hypothesis.

To test the statistical significance of these effects, the number of yards a team was penalized in a given year was converted to a $z$ score for each of the 17 seasons. The $17 z$ scores were then averaged for each team to get an overall measure of a team's history of penalties during this time period. These data, shown in Table 2, indicate that the teams with black uniforms are penalized significantly more than their rivals with nonblack uniforms, $p<.02$, thus providing strong support for our hypothesis. Football teams with black uniforms are indeed more aggressive than other teams, as measured by how much they are penalized. 
Table 2

Mean Number of Yards Penalized (in $z$ Scores) for National Football League Teams From 1970 to 1986

\begin{tabular}{lc}
\multicolumn{1}{c}{ Team } & $z$ \\
\hline LA RAIDERS & 1.19 \\
Buffalo & 0.63 \\
PITTSBURGH & 0.48 \\
Cleveland & 0.44 \\
Houston & 0.38 \\
Atlanta & 0.30 \\
CHICAGO & 0.29 \\
CINCINNATI & 0.27 \\
San Diego & 0.27 \\
Denver & 0.24 \\
Dallas & 0.23 \\
NEW ORLEANS & 0.10 \\
San Francisco & 0.09 \\
Detroit & 0.04 \\
Seattle & 0.02 \\
NY Jets & 0.01 \\
St. Louis & -0.01 \\
Washington & -0.07 \\
LA Rams & -0.09 \\
New England & -0.18 \\
Kansas City & -0.19 \\
Indianapolis & -0.19 \\
NY Giants & -0.32 \\
Tampa Bay & -0.41 \\
Philadelphia & -0.49 \\
Green Bay & -0.73 \\
Minnesota & -0.81 \\
Miami & -1.60 \\
\hline
\end{tabular}

Note. Teams in boldface capitals are those with black uniforms.

a Chicago's uniform is often thought to be black but is in fact a dark navy blue.

b These teams have only been in the National Football League since the 1976 season.

\section{The National Hockey League}

Recall that there are currently five teams with black uniforms in the NHL. However, only three of these teams-the Boston Bruins, the Chicago Black Hawks, and the Philadelphia Flyers-wore black uniforms during the entire 16-year period under investigation. The other two switched from nonblack to black during this time-the Pittsburgh Penguins during the 1979-1980 season and the Vancouver Canucks before the 1978-1979 season. The data from these latter two teams were naturally treated as part of the nonblack sample during the earlier years and as part of the black sample after they switched. These teams provide the most informative test of the link between uniform color and aggressiveness: Will the same team become more aggressive after switching to black uniforms?

In hockey, all penalties require the player who committed the infraction to sit out a portion of the game, during which time his team is outnumbered by the opposing team. Players sit out for 2,5 , or $10 \mathrm{~min}$ depending on the severity of the violation. The league office of the NHL provided us with the total number of minutes each team was penalized per season.

All teams were ranked in terms of the number of minutes penalized for each of the 16 seasons from 1970-1971 to 19851986. The average ranking of the teams with black uniforms (either 3,4 , or 5 teams depending on the year) was then calculated and compared to the average to be expected if they were no more likely to be penalized than their opponents (i.e., the average rank of all teams). As predicted, NHL teams that wear black uniforms-like their black-uniformed counterparts in professional football-are unusually aggressive: Their players spent more time in the penalty box than expected in each of the last 16 years.

To test the statistical significance of these effects, the number of minutes a team was penalized in a given year was converted to a $z$ score for each of the 16 seasons. The $16 z$ scores were then averaged for each team to get an overall measure of a team's history of penalties during this time. These data, shown in Table 3 , indicate that hockey teams with black uniforms incur substantially more penalties than their opponents. The difference between the black and nonblack teams on this measure is significant regardless of how the data from the two teams that switched uniforms (Pittsburgh and Vancouver) are treated: with Pittsburgh and Vancouver eliminated from the analysis, $p<.05$; with Pittsburgh and Vancouver contributing two data points in the analysis (one observation for their nonblack years and one for their black years), $p<.005$.

What happened when Pittsburgh and Vancouver switched to black uniforms? Did their penalty minutes increase? The relevant data, presented in Figure 1, indicate that they did, indeed. The difference in penalty minutes (in $z$ scores) before and after the uniform change is significant for Pittsburgh, $U=9.5, p<$

Table 3

Mean Number of Penalty Minutes (in z Scores) for National Hockey League Teams From 1970-1971 to 1985-1986

\begin{tabular}{|c|c|}
\hline Team & $z$ \\
\hline PHILADELPHIA & 2.01 \\
\hline PITTSBURGH $^{\mathrm{a}}$ & 0.88 \\
\hline VANCOUVER $^{\mathrm{b}}$ & 0.64 \\
\hline Edmonton & 0.58 \\
\hline Detroit & 0.44 \\
\hline BOSTON & 0.42 \\
\hline Quebec & 0.41 \\
\hline Toronto & 0.34 \\
\hline Vancouver $^{\mathrm{c}}$ & 0.05 \\
\hline CHICAGO & -0.02 \\
\hline Washington & -0.07 \\
\hline St. Louis & -0.09 \\
\hline Minnesota & -0.11 \\
\hline Los Angeles & -0.20 \\
\hline Winnepeg & -0.30 \\
\hline NY Rangers & -0.31 \\
\hline Pittsburgh ${ }^{d}$ & -0.31 \\
\hline Hartford & -0.34 \\
\hline NY Islanders & -0.35 \\
\hline Calgary & -0.40 \\
\hline Buffalo & -0.68 \\
\hline Montreal & -0.70 \\
\hline New Jersey & -0.78 \\
\hline
\end{tabular}

Note. Teams in boldface capitals are those with black uniforms.

a Mean for the black-uniformed years, from 1980-1981 to 1985-1986.

${ }^{\mathrm{b}}$ Mean for the black-uniformed years, from 1978-1979 to 1985-1986.

'Mean for nonblack-uniformed years, from 1970-1971 until 1977 1978.

d Mean for nonblack-uniformed years, 1970-1971 until 1978-1979. 


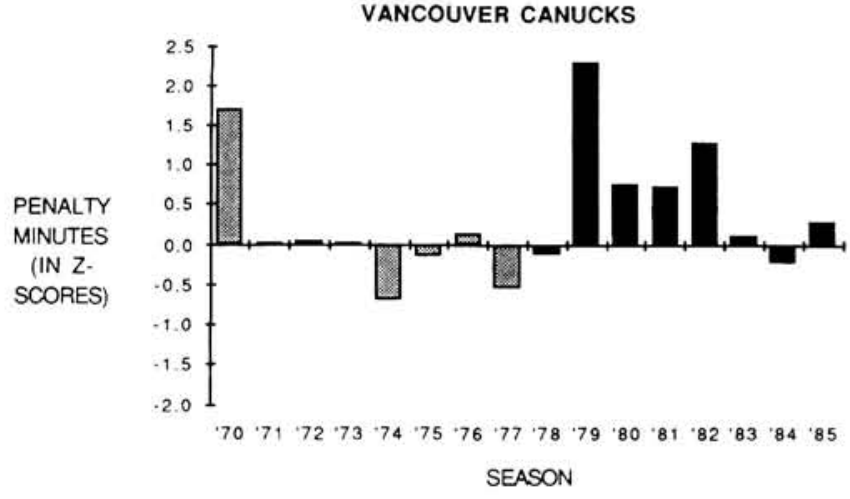

PITTSBURGH PENGUINS

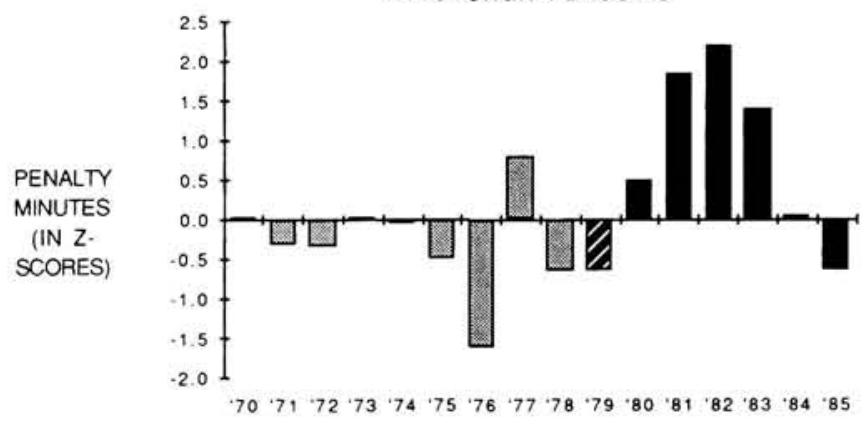

SEASON

Figure 1. Number of minutes penalized, in $z$ scores, for the years 19701971 (listed as "70") to $1985-1986$ (listed as " 85 ") for the two National Hockey League teams that switched from nonblack to black uniforms.

.05 , and marginally so for Vancouver, $U=25, p<.15{ }^{4}$ To rule out the possibility that these increases in penalty minutes may have stemmed from players playing more energetically and aggressively after any kind of change (including a change to a nonblack uniform), similar data were examined from another team. This team switched from blue-and-gold to red-and-green uniforms when they moved from Colorado (where they were the Rockies) to assume their new identity as the New Jersey Devils. However, unlike the two teams that switched to black uniforms, their change of colors (and locale) was not accompanied by an increase in penalties.

Even more direct evidence that the color of a team's uniform is connected to how often its players are penalized is obtained by comparing (a) the number of penalty minutes logged by the Pittsburgh Penguins during the first 44 games of the 1979-1980 season when they wore blue uniforms, with (b) the corresponding number during the final $\mathbf{3 5}$ games when they wore black. During the first 44 games they averaged 8 penalty min per game; after switching to black uniforms this average increased to 12 $\min (Z=2.16, p<.05)$.

\section{Discussion}

These data indicate that the uniform color of professional sports teams is related to how aggressively they play the game, as measured by how frequently they are penalized. Teams with black uniforms are overwhelmingly likely to rank near the top of their leagues in penalties. On those rare occasions when a team switched to black uniforms from another color, the switch was accompanied by a dramatic increase in penalties. This was true in one case even when the change occurred in the middle of the season, so that the "before" and "after" data were provided by the same players, being led by the same coaches, under the watchful eye of the same management.

We initiated this research with the hypothesis that wearing black uniforms would lead players to play more aggressively than they would with nonblack uniforms. However, there are at least two other possible explanations for the finding that teams with black uniforms are penalized more often than their rivals. First, because referees are also likely to associate the color black with evil and aggressiveness, they may view any given action as more malevolent if it is performed by a player in a black uniform. Thus, players in black uniforms may not play the game any more aggressively, but may simply be more likely to be penalized for actions that would be ignored if performed by players wearing nonblack uniforms. This explanation is by no means incompatible with the possibility that players in black uniforms actually play more aggressively: These two processes may be jointly responsible for the observed relationship between uniform color and penalties.

A second alternative explanation of our results is less interesting psychologically. According to this interpretation, the observed results are simply due to the fact that the management of certain teams want their players to play aggressively in the belief that doing so will make them more likely to win. ${ }^{5}$ Operating with this belief, these teams deliberately recruit players who are unusually aggressive. Furthermore, to be consistent with the aggressiveness theme of their organization, they choose black as the color of their team's uniform. According to this interpretation, then, the connection between black uniforms and elevated

\footnotetext{
${ }^{4}$ Of course, these data bear only on the difference in penalty levels before and after the uniform switch for each of these two teams, not on the possible differences in penalty records of all teams that might switch uniform colors. Thus, if one considers the present data to be the "population" of before and after records for these two teams, one simply notes the obvious change in penalty levels and ignores the question of statistical significance. These results are perhaps best viewed in this manner. Nevertheless, we report the results of the significance tests that would be appropriate if one were to consider the present data to be "samples" from the population of all possible "before" and "after" seasons for each of these two teams. For these tests, it is necessary to point out that the serial correlation between the penalty records for successive years for each team is essentially zero once the effect of uniform color has been partialed out ( $r=-.02$ for Vancouver and $r=.14$ for Pittsburgh). In other words, the data from different years (apart from the uniform switch) are statistically independent, and thus satisfy the assumptions of the relevant chance model underlying the Mann-Whitney test. Finally, the Mann-Whitney test on the Pittsburgh data does not include the records for the 1979-1980 season because Pittsburgh switched uniforms in the middle of that season.

${ }^{5}$ During the period under investigation, the black-uniformed teams in the NFL and the NHL did not win a significantly higher percentage of their games than teams with nonblack uniforms (Mann-Whitney Zs $<1$ ).
} 
penalty records is spurious: It stems from teams that happen to wear black deliberately stocking their rosters with "thugs."

Although this latter interpretation has some intuitive appeal (it is perfectly consistent with many people's image of the Los Angeles Raiders football team, for example), we believe that it cannot serve as an adequate account of the present results. It does not, for example, explain the fact that the two NHL teams that switched to black uniforms experienced an increase in penalties. For one of these teams, the Pittsburgh Penguins, the change took place in the middle of the season and thus was not accompanied by any change in players, coaches, or team philosophy. (The reason for the uniform switch was that Pittsburgh's professional football team, the Steelers, and baseball team, the Pirates, had just won the world championships of their respective sports-both while wearing black and gold uniforms. Thus, on the day after the Steelers won their championship, the Penguins announced that they were immediately switching to black and gold, Pittsburgh's colors of champions.)

At the very least, then, it is clear that such a differential recruitment of aggressive players by black- and nonblack-uniformed teams is neither necessary nor sufficient to explain the main findings reported here, although it may contribute to our results. Moreover, this artifactual interpretation of our results would be rendered even less compelling by any direct experimental evidence in support of the other two, more psychological, interpretations. It is to such evidence that we now turn. ${ }^{6}$

\section{Study 3: Biased Perceptions of the Aggressiveness of Black-Uniformed Teams}

To determine whether the penalty data reported in Study 2 might stem from the biased judgments of referees, we had subjects watch videotaped segments of a "staged" football game in which the defensive team was wearing either black or white uniforms. Subjects made a series of judgments about the defensive team's actions after each play. Because the actions presented on the videotape were staged by us, they depicted the same events in both the white and black versions. Despite this equivalence, we hypothesized that the association between black uniforms and meanness and aggressiveness would cause subjects to question the legality of the defensive team's actions more when they were wearing black uniforms than when they were wearing white.

\section{Method}

Procedure. The subjects were shown a videotape of two football plays involving the same two teams and were asked to make judgments about the actions of the defensive team in each. There were two versions of the videotape: one in which the defensive team wore black uniforms and one in which they wore white (the offensive team wore red in both versions). To ensure that any observed differences in subjects' ratings across the black and white versions of these plays could be attributed to the difference in uniform color, it was imperative that the two versions be identical on all other dimensions. With this in mind, we staged the plays ourselves. With the help of a group of former high school and college football players, we taped two versions of the two plays, making every effort to keep them identical. Each play was choreographed such that the actions of the defensive team were of borderline compliance with the rules of the game. The first play depicted two members of the defen- sive team grabbing the ball carrier, driving him back several yards, and throwing him to the ground with considerable force; the second play showed a ball carrier trying to leap over a tackler and being violently hit in mid-air by another member of the defensive team.

Of course, it is impossible to determine whether two versions of such a complex stimulus are in fact identical. As a result, we adopted a control procedure to guarantee the validity of our comparison of subjects' ratings of the two versions of the same play. In particular, we presented the videotapes to different groups of subjects in two different ways: in color to one group and with the color removed to the other group. By turning down the color and contrast dials on the videotape monitor, the color of the defensive team's uniforms became a dull grey that varied only slightly in brightness across the two versions. The experiment thus consisted of a $2 \times 2$ between-subjects design, with the color of the defensive team's uniforms (black/white) crossed with whether the tape was played with or without color (color/no-color). If no difference is observed in subjects' ratings of the two plays when the tapes are played without color, but there is a difference when the full-color versions are played, then we can safely attribute the latter effect to the difference in uniform color and not to any inherent asymmetry in the two versions of the same play.

Subjects were run in groups of 1 to 4 . Whenever 2 or more subjects were run in a session, they were separated into pegboard "booths" and asked not to comment on the videotape. The subjects then witnessed two plays with the defensive team in both plays wearing either black or white uniforms (or the "no-color" presentations of one of these). Before the videotape was shown, subjects were read the following instructions:

What we would like you to do is to make referees' judgments of a pair of football plays - plays filmed during a scrimmage between two small-college teams. You will be shown the first play only once, and in slow motion. Then the videotape machine will be stopped, and you will fill out a questionnaire concerning the play you have just witnessed. Once you have completed the questionnaire, the procedure will be repeated for the second play, and then there will be a final questionnaire for you to fill out. Please focus on the defensive team when watching the videotape.

The dependent measures consisted of two sets of questionnaire items. One set was filled out after each of the two plays. Subjects first indicated on a 9-point Likert scale how likely they would be to penalize the defensive team for the play in question, and then they chose one of eight descriptions of the aggressiveness of the defensive team's actions that were ordered in severity (e.g., $8=$ " a "cheap shot' designed to hurt the opposing player," $5=$ "legal, but exceedingly aggressive," and $1=$ "legal

\footnotetext{
${ }^{6}$ Before turning to the experimental evidence, there is a final aspect of our archival analyses that warrants discussion. Recall (Footnote 1) that teams wear "colored" uniforms for half of their games and "noncolored" uniforms for the other half. Accordingly, one might expect our two samples of black-uniformed teams to be particularly aggressive when wearing their colored uniforms. However, an analysis of the relevant data during the previous two NFL and NHL seasons revealed no such tendency in either sport (we performed this analysis on the data from the previous two seasons only because of the difficulty of obtaining the necessary penalty records of individual games). Nevertheless, we do not believe that this finding seriously weakens our thesis because a team's self-perception and/or public reputation no doubt carries over beyond individual games. Whatever effect a team's primary color has on its players or on the referees may very well generalize to those games in which it wears its noncolored uniforms. In support of this contention, we note that teams without exception identify themselves by their primary color and not by the color white. One frequently hears comments like "C"mon blue!" and "Let's go red!" but never "Hang in there, white!"
} 
and somewhat nonaggressive"). After watching both plays, subjects then answered three questions concerning their overall impressions of the defensive team. In particular, subjects put an $X$ on a 35-point dotted line to indicate their impression of the defensive team's "aggressiveness," their impression of the team's "dirtiness," and their assessment of the importance of "calling a 'tight' game" (i.e., one with a strict interpretation and implementation of the rules) in any game in which the defensive team was a participant to ensure that "aggression does not get out of hand."

Subjects. Two groups of subjects were run in this experiment. One was a group of 40 knowledgeable football fans from Cornell University. Ten of these subjects were run in each of the four experimental conditions. The other subjects were 20 referees of college and high school football games (with 8-35 years of experience at officiating). These subjects were run only in the "color" conditions of this experiment.

In essence, then, this investigation consisted of two experiments: one a complete $2 \times 2$ factorial experiment with 40 college students as subjects, and the other a partial replication (color conditions only) using experienced referees.

\section{Results}

Referees' ratings of individual plays. Were the referee subjects more inclined to penalize the defensive team when it was wearing black? To answer this question, the referees' penalty ratings for the two plays were analyzed by a 2 (uniform color) $\times 2$ (play) analysis of variance (ANOVA) with repeated measures on the second factor. This analysis showed the predicted main effect of uniform color to be significant, $F(1,18)=6.43$, $p<.05$. As can be seen in the relevant segments of Figure 2 , the referees were more inclined to penalize the defensive team if they saw the black versions of the two plays $(M \mathrm{~s}=7.2$ and 2.4 for Plays 1 and 2, respectively) than if they saw the white versions $(M \mathrm{~s}=5.3$ and 1.0$)$. There was also a significant, but unimportant, main effect of the play being rated, $F(1,18)=38.08$, $p<.0001$, but no significant interaction between uniform color and play, $F<1$.

Similar results were obtained on the referees' ratings of the aggressiveness of the defensive team's actions in these plays. As with the first measure, the ANOVA revealed a significant main effect of uniform color, $F(1,18)=6.52, p<.05$; a significant but unimportant main effect of play, $F(1,18)=33.05, p<$ .0001 ; and no interaction between these two variables, $F<1$. The defensive team was thought to be more aggressive by the referees who saw the black versions of the two plays ( $M \mathrm{~s}=6.1$ and 3.1 for Plays 1 and 2, respectively) than by those who saw the white versions $(M \mathrm{~s}=5.0$ and 2.2$)$.

College students' ratings of individual plays. Because the data provided by the college students included the crucial control conditions of showing the two plays with the color eliminated, their ratings were analyzed by a 2 (uniform color) $\times 2$ ("video condition"-i.e., color/no-color) $\times 2$ (play) ANOVA with repeated measures on the last factor. For subjects' penalty ratings, this analysis revealed the hypothesized significant interaction between uniform color and video condition, $F(1,36)=$ $16.62, p<.001$. As will be discussed in detail later, this interaction corresponds to the tendency for subjects to be more inclined to penalize the defensive team in the black versions of the plays, but only when the plays were shown in color. The only other significant effects were two meaningless main effects of
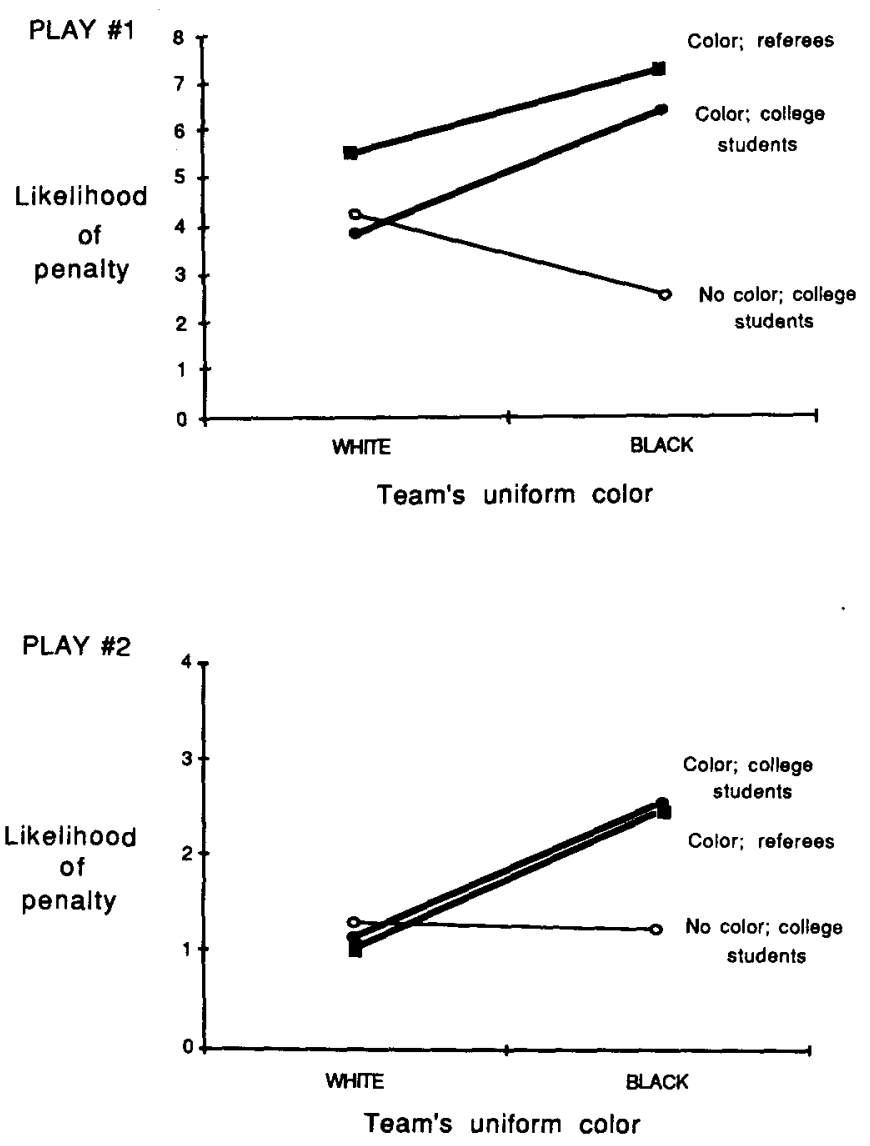

Figure 2. Subjects' mean inclination to penalize the defensive team, by condition.

play, $F(1,36)=40.81, p<.0001$, and video condition, $F(1$, 36) $=9.35, p<.005$.

The results are shown graphically in the relevant segments of Figure 2. By examining just the data from those subjects who saw the two plays in color, one can see that the results are nearly identical to those provided by the referees. Subjects who saw the black versions of the plays were more inclined to penalize the defensive team than were those who saw the white versions. This was true for both Play $1(M \mathrm{~s}=6.2$ vs. 3.7 for the black and white versions, respectively), $F(1,36)=7.02, p<.02$, and Play $2(M \mathrm{~s}=2.5$ versus 1.1$), F(1,36)=7.18, p<.02$.

In contrast, an examination of the data from those subjects who saw the two plays with the color removed reveals a very different, but equally important, pattern. Among these subjects, those who had witnessed the "black" versions of the two plays were not any more inclined to penalize the defensive team than were those who had seen the "white" versions. In fact, for Play 1 the "white" version of the play $(M=4.2)$ prompted marginally higher penalty ratings than the "black" version $(M=2.6), F(1$, $36)=2.89, p<.10$. (This produced a significant interaction between uniform color and videotape condition when the data from this play were analyzed separately, $F[1,36]=9.47, p<$ .01.) Thus, for this play at least, our attempt to make the "black" and "white" versions identical may have been unsuccessful. However, the direction of this asymmetry works against 
our hypothesis: The ratings of the subjects in these control conditions of the experiment indicate that the defensive team in the white version of the play may have been "objectively" more aggressive than in the black. For Play 2, the ratings of those who had seen the "black" $(M=1.2)$ and "white" $(M=1.3)$ versions were virtually identical, $F<1$, producing a significant interaction between uniform color and video condition for this play as well, $F(1,36)=4.12, p<.05$. These control conditions, then, demonstrate that the tendency of both the college students and the referees to be more inclined to penalize the defensive team when it was wearing black cannot be attributed to any inherent difference in the two versions of the two plays.

Similar results were obtained on the college students' ratings of the defensive team's aggressiveness in these two plays. The $2 \times 2 \times 2$ ANOVA revealed the hypothesized significant interaction between uniform color and video condition, $F(1,36)=$ $15.34, p<.001$. The analysis also produced a significant main effect of play, $F(1,36)=19.72, p<.0001$, and a marginally significant effect of video condition, $F(1,36)=3.24, p<.10$. As with the penalty ratings, when the plays were seen in color, those who had seen the black versions of the plays saw marginally more aggressiveness on the part of the defensive team than those who had seen the white versions. This was true of both Play $1(M \mathrm{~s}=5.0$ vs. 3.9 , for the black and white versions, respectively), $F(1,36)=3.46, p<.10$, and Play $2(M \mathrm{~s}=3.5$ and $2.4), F(1,36)=3.20, p<.10$. In contrast, when seen without color, Play 1 yielded higher aggressiveness ratings in the "white" condition $(M=4.8)$ than in the "black" condition $(M=3.4)$, $F(1,36)=5.62, \mathrm{p}<.05$, and Play 2 yielded no difference between conditions $(M \mathrm{~s}=2.4$ and 2.5$), F<1$. (The interaction between uniform color and video condition for each play separately was as follows: For Play $1, F[1,36]=8.93, p<.01$; for Play $2, F[1,36]=1.33, n s$.)

Summary assessments of the defensive team. Recall that after watching both plays, subjects rated the overall aggressiveness and "dirtiness" of the defensive team and indicated how likely they would be to call a "tight" game in any contest in which the defensive team was one of the participants. For the referee subjects, the results were strong and consistent. Compared to their counterparts who had seen the white versions of the two plays, those who had seen the black versions rated the defensive team as significantly more aggressive $(M \mathrm{~s}=23.3$ vs. 10.0$), F(1$, $18)=8.67, \mathrm{p}<.01$, and marginally more $\operatorname{dirty}(M \mathrm{~s}=16.1 \mathrm{vs}$. 9.2), $F(1,18)=2.84, p<.11$, and, perhaps most important, were significantly more inclined to call a tight game $(M \mathrm{~s}=27.5$ vs. 12.7$), F(1,36)=16.47, \mathrm{p}<.001$.

The analysis of the college students' ratings on these measures revealed consistent, but for the most part less strong, results. After watching the tapes in color, those who had seen the black versions of the plays tended to give higher ratings on all three measures than those who had seen the white versions; in contrast, there were no such differences in subjects' ratings when the plays were seen with the color removed. However, the crucial interaction between uniform color and video condition was significant for the dirtiness ratings only, $F(1,36)=5.75, p<.05$ $(M \mathrm{~s}=17.1$ vs. 9.8 for those who had seen the black and white versions in color; $M \mathrm{~s}=11.4$ vs. 15.6 for those who had seen the same versions, respectively, with the color removed).

\section{Discussion}

These data provide strong support for a "social perception" interpretation of the observed tendency for professional sports teams that wear black uniforms to be penalized more than their rivals. Teams that wear black uniforms receive harsher treatment from the referees. Because we associate the color black with meanness and aggressiveness, we "see" more aggressiveness or more malevolent intent in the actions of players wearing black uniforms. When asked to assume the role of a referee, the subjects in this experiment were more likely to penalize the defensive team when its players were wearing black uniforms than when they were wearing white, despite the fact that the actions performed by the players in black uniforms were not in any objective sense more aggressive or illegal. Perhaps the most telling evidence that the inordinate number of penalties amassed by black-uniformed teams is at least partially due to the judgments of referees is that our sample of experienced officials-who actually make the calls in real college and high school football games-indicated that they would call a "tighter" game when the team they had seen was wearing black uniforms.

Having thus obtained support for the "social perception" interpretation of the excessive number of penalties amassed by teams that wear black uniforms in professional sports, it is important to determine whether this is the sole cause of the observed effect. To address this question, we now turn to an experiment designed to test the "self-perception" interpretation of this effect: whether wearing black uniforms actually leads players to behave more aggressively.

\section{Study 4: Inducing Aggression by the Wearing of Black Uniforms}

There are a couple of difficulties that confront any attempt to test whether wearing a black uniform tends to make a person more aggressive. First, any such test is fraught with the usual ethical problems involved in all research on human aggression. Second, in light of the results of Study 3, any aggression elicited in such an experiment would have to be objectively recorded rather than assessed by human judges. The usual solution to these twin problems is to use some version of the bogus shock paradigm (Buss, 1961). However, we chose not to use this procedure because of the difficulty in finding subjects who-given the publicity of Milgram's $(1965,1974)$ work-would not view the proceedings with extreme suspicion.

Our solution to these problems was to collect "behavioroid" data (cf. Carlsmith, Ellsworth, \& Aronson, 1976) in the form of subjects' intended aggressive behavior. Volunteers for an experiment on competition were led to believe that they would be vying against other subjects in several competitive events. They were also led to believe that they could exercise some control over which events they were to participate in by selecting their 5 most preferred events from a list of 12 . The 12 events varied in the amount of aggressiveness they called for, allowing us to use subjects' choices as a measure of their readiness to engage in aggressive action. By means of a suitable cover story, we elicited subjects' choices twice: once individually when wearing their usual clothes, and later as a team of 3 wearing black or white 
jerseys. We hypothesized that wearing black jerseys would induce subjects to view themselves as more mean and aggressive and thus would produce more of a "group shift" toward aggressive choices by subjects wearing black jerseys than by those wearing white (Drabman \& Thomas, 1977; Jaffe, Shapir, \& Yinon, 1981; Jaffe \& Yinon, 1979).

\section{Method}

Overview. Subjects participated in groups of 3 in an experiment ostensibly on the "psychology of competition." Each group was told that they would be competing against another team of 3 on a series of five games of everyone's choosing. To find out their preferences, they were asked to individually rank order 5 activities from a group of 12 . After making their choices, the subjects were outfitted in either white or black uniforms in the guise of facilitating team identity. Then, while the experimenter was supposedly administering instructions to the other team, the 3 subjects were told to discuss their individual choices and to decide as a group on a rank ordering of the five activities they would like to include in the competition. This second ranking allowed us to assess whether subjects would choose more aggressive games as a group after donning black uniforms than after putting on white uniforms. Finally, as an auxiliary measure of aggression, subjects were administered a brief Thematic Apperception Test (TAT; Murray) to assess their level of aggressive ideation.

Subjects. The subjects were 72 male students from Cornell University who were paid $\$ 3$ for their participation. They were run in groups of 3 , with the members of each group unacquainted with one another.

Procedure. As the subjects reported for the experiment they were brought together in one room and led to believe that another group of 3 subjects was assembling in a different room. Subjects were told, that

You will be competing, as a team, on a series of five games against another group of three subjects who are waiting in the next room. I matched the two teams for size as you came in, so the contests should be fair. This study is designed to mimic real-life competition as closely as possible . . . [and so] . . . we want you to choose the games you want to play.

Subjects were then given a list of descriptions of 12 games and were asked to indicate, individually, which games they would like to play. They were asked to choose 5 of the 12 games and to rank order those 5 . After reminding the subjects not to discuss their choices with one another, the experimenter left the room, ostensibly to elicit the choices of the other team.

Upon his return, the experimenter collected the subjects' individual choices and stated that "now I would like you to make a group decision as to which games you will play, because many times people's preferences are so divergent that we need to use a group choice to serve as a tie-breaker when deciding on which games to play." The experimenter further explained that "to make this experiment more like real-world competition and to build team cohesion, I would like you to put these uniforms on over your shirts. From now on you will be referred to as the black [white] team." The subjects were then given black or white uniforms with silver duct-tape numerals $(7,8$, and 11$)$ on the backs.

The experimenter once again left the room to allow the subjects to make their group choices and then returned after $5 \mathrm{~min}$. He then explained,

Now that I have everyone's individual and team selections, I will go and set up the five games that received the most votes. While I am doing this, I want you to complete a standard psychological task to get all of you in the same state of mind before we start.

Subjects were asked to write a brief story about a scene depicted in a TAT card (Card 18 BM from Murray's, 1943, original series). Subjects were given $4 \mathrm{~min}$ to write a story based on the following questions: (a) What is happening in the picture? (b) What is being thought by the characters in the picture? (c) What has led up to this picture? and (d) What will happen to the characters in the picture?

After 4 min the experimenter returned, collected the TAT protocols, and thoroughly debriefed the subjects. All subjects seemed surprised (and many disappointed) to learn that the experiment was over. The debriefing interview also made it clear that none of the subjects had entertained the possibility that the color of their uniforms might have been the focus of the experiment.

Dependent measures. The primary dependent measure in this experiment was the level of aggressiveness involved in the games subjects wanted to include in the competition. A group of 30 subjects had earlier rated a set of descriptions of 20 games in terms of how much aggressiveness they involved. The 12 games that had received the most consistent ratings and that represented a wide spectrum of aggressiveness were then used as the stimulus set in this experiment. These 12 games were ranked in terms of these aggressiveness ratings and assigned point values consistent with their ranks, from the most aggressive $(12,11$, and 10 points for "chicken fights," "dart gun duel," and "burnout," respectively) to the least aggressive (1, 2, and 3 points for "basket shooting," "block stacking," and "putting contest," respectively). Subjects were asked to choose the five games that they wanted to include in the competition and to rank order their five choices in terms of preference. To get an overall measure of the aggressiveness of each subject's preferences, we multiplied the point value of his first choice by 5 , his second choice by 4 , and so forth, and then added these five products. When comparing the choices made by the subjects individually (without uniforms) with those made by the same individuals as a group (with uniforms), we compared the average individual choices of the 3 subjects with their group choice.

The second dependent measure in this experiment was subjects' responses to the TAT card. Subjects' TAT stories were scored on a 5-point aggressiveness scale (Feshbach, 1955). Stories devoid of aggression received a score of 1 , those with a little indirect aggression a score of 2 , those with considerable indirect or a little direct aggression a 3, those with direct physical aggression a 4 , and those with graphic violence a 5 . These ratings were made by two judges who were unaware of the subjects' condition. The judges' ratings were in perfect agreement on $47 \%$ of the stories and were within one point on another $48 \%$.

\section{Results}

The mean levels of aggressiveness in subjects' individual and group choices are presented in Table 4. As expected, there was no difference in subjects' individual choices across the two groups $(M s=113.4$ vs. 113.5$)$, because they were not wearing different-colored uniforms at the time these choices were made. However, the subjects who then donned black uniforms subsequently chose more aggressive games (mean change in aggressiveness $=16.8$ ), whereas those who put on white uniforms showed no such shift (mean change $=2.4$ ). A $2 \times 2$ mixed between/within ANOVA of subjects' choices yielded a significant interaction between uniform color and individual/group choice, $F(1,22)=6.14, p<.05$, indicating that the pattern of choices made by subjects in black uniforms was different from that of those wearing white. Wearing black uniforms induced subjects to seek out more aggressive activities, matched-pairs $t(11)=3.21, p<.01$; wearing white uniforms did not, matchedpairs $t(11)=1.00, n s$.

The subjects who wore black uniforms also tended to express more aggressive ideation $(M=3.20)$ in their TAT stories than 
Table 4

Mean Level of Aggressiveness Contained in Subjects' Chosen Activities, by Condition

\begin{tabular}{|c|c|c|c|c|c|c|}
\hline \multirow{2}{*}{$\begin{array}{l}\text { Uniform } \\
\text { color }\end{array}$} & \multicolumn{2}{|c|}{$\begin{array}{l}\text { Mean } \\
\text { individual } \\
\text { choice } \\
\text { (without } \\
\text { uniforms) }\end{array}$} & \multicolumn{2}{|c|}{$\begin{array}{c}\text { Group choice } \\
\text { (with } \\
\text { uniforms) }\end{array}$} & \multicolumn{2}{|c|}{$\begin{array}{c}\text { Change in } \\
\text { aggressiveness }\end{array}$} \\
\hline & $M$ & $S D$ & $M$ & $S D$ & $M$ & $S D$ \\
\hline White & 113.4 & 23.9 & 115.8 & 25.4 & +2.4 & 8.5 \\
\hline Black & 113.5 & 18.4 & 130.3 & 22.9 & +16.8 & 18.1 \\
\hline
\end{tabular}

did subjects wearing white uniforms ( $M=2.89$ ), although this difference was not significant, $t<1$.

\section{Discussion}

The results of this experiment support the hypothesis that wearing a black uniform can increase a person's inclination to engage in aggressive behavior. Subjects who wore black uniforms showed a marked increase in intended aggression relative to those wearing white uniforms. These results, in conjunction with the findings of Study 3, suggest that the excessive penalties amassed by black-uniformed teams in professional sports stem from two distinct processes-their own aggressiveness and harsher treatment by the referees.

It should be noted, however, that at this point we can place more confidence in the role played by the referees than by the players themselves. The effect of referees' judgments was directly assessed by having real referees do what they are paid to do-make judgments about the legality of various actions in the game of football. In contrast, our demonstration that wearing black uniforms increased subjects' willingness to act aggressively involved only intended aggression and did not employ any real football or hockey players as subjects. It would have been interesting to have allowed our subjects to compete against one another in their chosen activities and seen whether those in black jerseys performed more aggressively. We refrained from doing so because of ethical and methodological difficulties (i.e., the difficulty in measuring aggressiveness in light of the results of Study 3). Nevertheless, the results of this experiment make the important point that in a competitive setting at least, merely donning a black uniform can increase a person's willingness to seek out opportunities for aggression. If the wearing of a black uniform can have such an effect in the laboratory, there is every reason to believe that it would have even stronger effects on the playing field (or rink), where many forms of aggression are considered acceptable behavior.

\section{General Discussion}

Previous research in the social psychological literature has demonstrated that the cues inherent in certain uniforms can influence a person's willingness to harm another individual (Johnson \& Downing, 1979). With this in mind, we investigated whether the widespread association between the color black and evil and death (Adams \& Osgood, 1973) might lead to elevated levels of aggressiveness on the part of people wearing black uniforms. In particular, we examined whether the teams with black uniforms in two professional "contact" sports tend to be unusually aggressive, as measured by how frequently they are penalized. As predicted, teams with black uniforms in the NFL and the NHL were penalized significantly more often during the last 17 years than their rivals in nonblack uniforms. Furthermore, those teams that switched from nonblack to black uniforms during this time period experienced an immediate and dramatic increase in penalties. The results of our two laboratory experiments indicate that the effect of wearing black uniforms on a team's history of penalties may be attributable to two distinct processes. Study 3 demonstrated that players in black uniforms are judged more harshly than those in white uniforms by nonpartisan judges and thus are more likely to be penalized for actions that would be overlooked if performed by members of another team. In Study 4, subjects wearing black uniforms were more inclined than their white-uniformed counterparts to seek out opportunities for aggressive competition, providing some initial support for the idea that football and hockey players who wear black uniforms actually play more aggressively than their rivals.

These results raise several intriguing questions. Perhaps the simplest of these is whether our central findings are best thought of as a discrete difference between teams wearing black versus nonblack uniforms, or as a continuous difference between teams whose uniforms vary less abruptly in color and malevolent appearance. One way to address this question is to examine the relationship between the malevolence ratings in Study 1 and the penalty records in Study 2 . The correlation between the malevolence ratings and penalty records for all 28 NFL teams is $.40, p<.05$, and for all $21 \mathrm{NHL}$ teams is $.48, p<.05$. These correlations, however, incorporate the significant dichotomous difference between the penalty records of teams with black and nonblack uniforms. When this black/nonblack difference is controlled through a partial correlation analysis, the relationship between the malevolent appearance of a team's uniform and its history of penalties is reduced considerably in the NFL $(r=.13)$ and disappears completely in the NHL $(r=.02)$. Thus, it appears that the "uniform effect" reported above is a discrete effect of black versus nonblack uniforms, although there is the faintest suggestion in the data from the NFL that this discrete difference might constitute the most robust part of a more subtle continuous effect of uniform color. It remains for further research to conclusively resolve this question.

A second question raised by this research concerns the generality of the effect of uniform color on aggression. It is very unlikely that donning any black uniform in any situation would make a person more inclined to act aggressively. We do not believe, for example, that the black garments worn by Catholic clergymen or Hassidic Jews make them any more aggressive than their secular peers. Rather, it would seem to be the case that the semantic link between the color black and evil and aggressiveness would be particularly salient in domains that already possess overtones of competition, confrontation, and physical aggression. Thus, the kind of results that we have reported may be most likely to be observed in precisely the domain chosen for this investigation: Physical dominance and in- 
timidation are an inherent part of many sports, with various forms of aggression not only tolerated, but actively encouraged.

With this in mind, any speculation about other domains in which analogous effects might be obtained should center on those areas that also possess inherent elements of force and confrontation. The actions of uniformed police officers and prison guards may be one such area. Is it the case, in other words, that the color of the uniforms worn by such individuals influences the amount of aggressiveness they exhibit in performing their duties? This intriguing possibility could readily be tested by examining archival indices of aggression and violence involving police officers and prison guards, such as charges of police brutality and assaults on police officers (cf. Mauro, 1984). These analyses could involve both cross-sectional comparisons of police departments (or prisons) with different-colored uniforms, as well as longitudinal comparisons within departments that have changed uniform colors. We should point out, however, that we strongly doubt whether there are any police departments or penal institutions in this country that issue black uniforms to their personnel, possibly out of implicit recognition of this article's central thesis. Nevertheless, the uniforms of police officers and prison guards do vary in color a great deal, from dark blue to light khaki. Thus, one might still expect to find an effect of uniform color on aggressiveness if the subsequent research alluded to above indicates that the uniform effect we have documented is indeed more than a simple dichotomous difference between black and nonblack uniforms.

The third, and in many ways most important, question raised by this research concerns the exact mechanisms by which the color of a team's uniform has an effect on its history of penalties. We have described two general mechanisms to account for such an effect, one involving the judgments of referees and the other involving the behavior of the players themselves. The way in which a visual stimulus like a black uniform can affect the judgment of referees is rather straightforward. There is now a large literature documenting how people's mental sets can distort their judgment and perception of events (Gilovich, 1981, 1983; Langer \& Abelson, 1974; Nisbett \& Ross, 1980; Snyder \& Uranowitz, 1978; Zadny \& Gerard, 1974). However, the ways in which wearing a black uniform might affect the behavior of the wearer may seem less clear.

< Our own explanation of this phenomenon centers upon the implicit demands on one's behavior generated by wearing a particular kind of uniform. To wear a certain uniform is to assume a particular identity, an identity that not only elicits a certain response from others but also compels a particular pattern of behavior from the wearer (Stone, 1962). Wearing an athletic uniform, for example, thrusts one into the role of athlete, and leads one to "try on" the image that such a role conveys. When the uniform is that of a football or hockey player, part of that image-and therefore part of what one "becomes"-involves toughness, aggressiveness, and "machismo." These elements are particularly salient when the color of one's uniform is black. Just as observers see those in black uniforms as tough, mean, and aggressive, so too does the person wearing that uniform (Bem, 1972). Having inferred such an identity, the person then remains true to the image by acting more aggressively in certain prescribed contexts.

More broadly construed, then, our results serve as a reminder of the flexible or "situated" nature of the self (Alexander \& Knight, 1971; Goffman, 1959; Mead, 1934; Stone, 1962). Different situations, different roles, and even different uniforms can induce us to try on different identities. Around those who are socially subdued or shy, we become a vivacious extrovert; around true socialites, we may retreat into the more reserved role of resident intellectual. In the presence of family members, we play the role of learned scholar granted us by our advanced degrees; in the company of Nobel laureates, we think of ourselves less as scientists and more as amateur musicians, devoted fathers and mothers, or fun-loving globetrotters. Some of these identities that we try to adopt do not suit us, and they are abandoned. This sustains our belief that personalities are stable and reassures us that at our core lies a "true" self. To a surprising degree, however, the identities we are led to adopt do indeed fit, and we continue to play them out in the appropriate circumstances. Perhaps the best evidence for this claim is the existence of identity conflict, such as that experienced by college students who bring their roommates home to meet their parents. This is often a disconcerting experience for many students because they cannot figure out how they should behave or "who they should be"-with their parents they are one person and with their friends they are someone else entirely.

The present investigation demonstrates how a seemingly trivial environmental variable, the color of one's uniform, can induce such a shift in a person's identity. This is not to suggest, however, that in other contexts the direction of causality might not be reversed. The black outfits worn by gangs like the Hell's Angels, for example, are no doubt deliberately chosen precisely because they convey the desired malevolent image. Thus, as in the world portrayed in the typical American Western, it may be that many inherently evil characters choose to wear black. However, the present investigation makes it clear that in certain contexts at least, some people become the bad guys because they wear black.

\section{References}

Adams, F. M., \& Osgood, C. E. (1973). A cross-cultural study of the affective meanings of color. Journal of Cross-Cultural Psychology, 4 , 135-156.

Alexander, C. N., \& Knight, G. (1971). Situated identities and social psychological experimentation. Sociometry, 34, 65-82.

Bem, D. J. (1972). Self-perception theory. In L. Berkowitz (Ed.), $A d$ vances in experimental social psychology (Vol. 6, pp. 1-62). New York: Academic Press.

Buss, A. H. (1961). The psychology of aggression. New York: Wiley.

Carlsmith, J. M., Ellsworth, P. C., \& Aronson, E. (1976). Methods of research in social psychology, Reading, MA: Addison-Wesley.

Drabman, R. S., \& Thomas, M. H. (1977). Children's imitation of aggressive and prosocial behavior when viewing alone and in pairs. Journal of Communication, 27, 199-205.

Feshbach, $\mathrm{S}$. (1955). The drive-reducing function of fantasy behavior. Journal of Abnormal and Social Psychology, 50, 3-11.

Gilovich, T. (1981). Seeing the past in the present: The effect of associations to familiar events on judgments and decisions. Journal of Personality and Social Psychology, 40, 797-808.

Gilovich, T. (1983). Biased evaluation and persistence in gambling. Journal of Personality and Social Psychology, 44, 1110-1126.

Goffman, E. (1959). The presentation of self in everyday life. New York: Doubleday. 
Jaffe, Y., Shapir, N., \& Yinon, Y. (1981). Aggression and its escalation. Journal of Cross-Cultural Psychology, 12, 21-36.

Jaffe, Y., \& Yinon, Y. (1979). Retaliatory aggression in individuals and groups. European Journal of Social Psychology, 9, 177-186.

Johnson, R. D., \& Downing, L. L. (1979). Deindividuation and valence of cues: Effects on prosocial and antisocial behavior. Journal of Personality and Social Psychology, 37, 1532-1538.

Langer, E. J., \& Abelson, R. P. (1974). A patient by any other name . . .: Clinician group difference in labeling bias. Journal of Consulting and Clinical Psychology, 42, 4-9.

Mauro, R. (1984). The constable's new clothes: Effects of uniforms on perceptions and problems of police officers. Journal of Applied Social Psychology, 14, 42-56.

Mead, G. H. (1934). Mind, self, and society. Chicago: University of Chicago Press.

Milgram, S. (1965). Some conditions of obedience and disobedience to authority. Human Relations, 18, 57-76.

Milgram, S. (1974), Obedience to authority. New York: Harper.

Murray, H. A. (1943). Thematic Apperception Test manual. Cambridge, MA: Harvard University Press.

Nisbett, R., \& Ross, L. (1980). Human inference: Strategies and shortcomings of social judgment. Englewood Cliffs, NJ: Prentice-Hall.
Snyder, M., \& Uranowitz, S. W. (1978). Reconstructing the past: Some cognitive consequences of person perception. Journal of Personality and Social Psychology, 36, 941-950.

Stone, G. P. (1962). Appearance and the self. In A. M. Rose (Ed.), Human behavior and social process (pp. 86-118). Boston: Houghton Mifflin.

Turner, V. (1967). The forest of symbols: Aspects of Ndembu ritual. Ithaca, NY: Cornell University Press.

Williams, J. E. (1964). Connotations of color names among Negroes and Caucasians. Perceptual and Motor Skills, 18, 721-731.

Williams, J. E., \& McMurty, C. A. (1970). Color connotations among Caucasian 7 th graders and college students. Perceptual and Motor Skills, 30, 701-713.

Williams, J. E., Moreland, J. K., \& Underwood, W. I. (1970). Connotations of color names in the U.S., Europe, and Asia. Journal of Social Psychology, 82, 3-14.

Zadny, J., \& Gerard, H. B. (1974). Attributed intentions and informational selectivity. Journal of Experimental Social Psychology, 10, 3452 .

Received November 14, 1986

Revision received July 15,1987

Accepted July 30, 1987

\section{Call for Nominations for the Editor of JEP: General}

The Publications and Communications Board has opened nominations for the editorship of the Journal of Experimental Psychology: General for the years 1990-1995. Sam Glucksberg is the incumbent editor. Candidates must be members of APA and should be available to start receiving manuscripts in early 1989 to prepare for issues published in 1990 . Please note that the $\mathrm{P} \& \mathrm{C}$ Board encourages more participation by women and ethnic minority men and women in the publication process and would particularly welcome such nominees. To nominate candidates, prepare a statement of one page or less in support of each candidate. Submit nominations no later than February 15, 1988, to

$$
\begin{gathered}
\text { Donald J. Foss } \\
\text { Department of Psychology } \\
\text { University of Texas } \\
\text { Austin, Texas } 78712
\end{gathered}
$$

Other members of the search committee are James J. Jenkins, Jean Mandler, J. E. R. Staddon, and Saul Sternberg. 